\title{
Effectiveness of Theory of Planned Behavior-Based Educational Intervention on Newborn Care in Pregnant Mothers: A quasi-experimental study
}

\section{Azamalsadat Navabi}

Arak University of Medical Sciences

mohsen shamsi (D mohsen_shamsi1360@yahoo.com)

Arak University of Medical Sciences https://orcid.org/0000-0003-4033-8041

Mahboobeh Khorsandi

Arak University of Medical Sciences

Maryam Zamanian

Arak University of Medical Sciences

Research article

Keywords: Newborn Care, Danger Signs, Pregnant Mother, Theory of Planned Behavior, Education

Posted Date: June 19th, 2020

DOI: https://doi.org/10.21203/rs.3.rs-35616/v1

License: (c) (i) This work is licensed under a Creative Commons Attribution 4.0 International License. Read Full License 


\section{Abstract}

Background and Purpose: The neonatal period is one of the most sensitive stages of life, requiring proper understanding and attentive care. Accordingly, this study aimed to investigate the effectiveness of theory of planned behavior-based educational intervention on newborn care in pregnant mothers.

Methodology: This study was conducted as a quasi-experimental research on 100 pregnant mothers who were randomly assigned to two groups of intervention $(\mathrm{N}=50)$ and control $(\mathrm{N}=50)$. The data were collected using a theory of planned behavior-based questionnaire. Considering the effective constructs of this theory, the educational intervention was performed in the form of four 60 -minute education sessions in one month in the intervention group. One month after delivery, the data were recollected from both groups and analyzed using statistical tests.

Findings: The mean and standard deviation of the mothers' age in both intervention and control groups were $26.14 \pm 4.7$ and $26.10 \pm 5.19$, respectively $(p=0.48)$. Before the educational intervention, the behavioral intention of the intervention group was 3.33 (out of 5), which significantly increased to 4.54 after the educational intervention $(p<0.001)$. In addition, the performance of mothers regarding neonatal care was significantly enhanced from 2.86 to 4.64 one month after the delivery $(p=0.001)$.

Conclusion: The theory of planned behavior-based educational intervention, along with active follow-ups, led to better and more principled behavioral intention and care provided by pregnant mothers to their newborn infants. Therefore, providing theory of planned behavior-based education in other healthcare centers is recommended.

\section{Introduction}

The neonatal period (first 28 days after birth) is one of the most sensitive stages of life, requiring proper understanding and attentive care. Any failure to do so causes irreparable damage and increases infant mortality [1]. Globally, infant mortality is still a critical public health challenge, with the highest mortality rates among children under five [2].

About 7.7 million children under five die worldwide every year, out of which approximately 3.1 million infants die during infancy and nearly all of these deaths (99\%) occur in developing countries. According to the estimations reported by the World Health Organization, infant mortality makes up $45 \%$ of the deaths among children under five and more than one-third of these mortalities occur during the first 24 hours of birth [3].

In developed countries, including the United States, two-thirds of all deaths during the first year of life occur in infancy. The annual mortality rate in the first year of life exceeds that until the seventh decade of life [4-5]. In Iran, infant mortality rate (IMR( is 12 and mortality rate in children aged 1-4 were estimated to be 14.5 per 1000 live births [6-7]. 
Genetics and environment are two factors influencing infants' health. Genetic effects cannot be controlled by the individual, but environmental effects such as motherhood skills in neonatal care can be learned. Accordingly, promoting awareness and ability of mothers, especially the nulliparous pregnant women, in every society regarding the ways of coping with problems of newborns can be effective in enhancing newborns' health [8]. As reported by the World Health Organization, if the knowledge and awareness of parents is promoted properly, the lives of two-thirds of children dying annually because of different reasons will be saved [9-10].

However, it was found that only $37 \%$ of mothers in a study in Saudi Arabia [11], 30\% of mothers in the study of Uchenna in Nigeria[12], 58\% of mothers in the study of Sandberg in Uganda [13] and $20 \%$ of mothers in the study of Bulto in Ethiopia [14] were aware of newborn care, and all these studies emphasized on the necessity of educating mothers in this area.

On the other hand, Memon et al. reported the weak performance of Pakistani mothers [15] and Waiswa also revealed weak newborn care methods used by mothers in Eastern region of Uganda [16].

As implementing educational programs for empowering mothers without the need for modern equipment can be very cost-effective in reducing mortality rate and huge costs of mental disabilities resulted from defects in pregnancy and newborn care, the importance of educating mothers is tangible in any society.

Alam [17], Murthy [18] and Wu [19] in their studies conducted in Bangladesh, India and China, respectively, have also emphasized on the necessity of educating pregnant mothers regarding newborn care and conducting more research in this regard.

This study has employed the theory of planned behavior, for it has the appropriate constructs, including behavioral intention, for the purpose of the study. This theory is used when we cannot measure people's actual behaviors and so, we use their equivalents, that is, behavioral intentions. Similarly, we cannot measure the mothers' behavior of newborn care as long as the baby has not been born. However, their behavior of newborn care can be predicted and assessed by measuring the behavioral intention of the pregnant mothers in this regard. Therefore, this theory has been used in this study.

According to this theory, people enact behaviors when they expect a benefit and value out of those behaviors and this expectation is based on individual judgment [20]. Education based on this theory has been positively assessed in various areas of healthcare for vulnerable groups [21-22].

Figure $<$ link rid="fig2" $>1</$ link $>-1$ shows the theory of planned behavior.

It is worth to note that most of the previous research has been non-interventional and focused on the problems of premature infants and little research is available on healthy newborn care. Accordingly, considering multiple problems of newborn care and the importance of educating mothers on taking care of their newborns, this study was designed and conducted aiming to determine the efficiency of theory of planned behavior-based educational intervention on enhancing newborn care by mothers. 


\section{Materials And Methods}

This study was an interventional and quasi-experimental research. The study population included all third-trimester pregnant mothers who referred to the health centers located in the city of Arak, Iran. Inclusion criteria were being a nulliparous pregnant woman and willingness to participate in the study. Exclusion criteria were reluctance to continue participating in the study and being absent more than twothirds of the education sessions.

The sample size required for this study was determined as 100 people. According to the study of Ghasemi et al. [21] and considering type I error of $5 \%$ and type II error of $10 \%$ based on the performance construct, the sample size of 40 participants was obtained in each group. Finally, considering the sample loss, 50 participants were included in each group of intervention and control.

\section{See formula 1 in the supplementary files.}

In order to sample among health centers located in the city of Arak, 4 health centers out of the total of 24 centers were selected based on socioeconomic conditions and were randomly divided into two groups of intervention and control (two centers for each). 50 mothers from the intervention centers and 50 mothers from the control centers were selected through convenience sampling and included in the study according to the family file number available in the health centers.

In the study, the primary outcomes included awareness and constructs of the theory of planned behavior, including attitude, subjective norm and perceived behavioral control. The secondary outcomes included intention and behavior of pregnant mothers regarding their newborn babies.

In this study, first the information were collected from both intervention and control groups through a reliable and valid questionnaire before the intervention. Then, the intervention group received TPB-based educational intervention for one month and the control group received routine educations provided by the centers. At last, the information were collected from both intervention and control groups one month after delivery.

\section{Data Collection Tool}

The data collection tool in this study was a questionnaire composed of the following sections:

Demographic Information: including the mother's age, parents' job, parents' education, pregnancy age and the age of marriage

The Mothers' Awareness Assessment on Newborn Care: including 8 multiple-choice questions completed by mothers

Theory of Planned Behavior Section: including the following constructs: 
1. Mothers' Attitudes: including four questions to be answered on a 5- point Likert scale (totally agree: 5 points, agree: 4 points, no idea: 3 points, disagree: 2 points, and totally disagree: 1 point). In this study, the mothers' attitudes towards the benefits of proper newborn care and the adverse consequences of improper care were measured. The more desirable the attitude toward a behavior is, the more likely the behavior is enacted.

2. Mothers' subjective norms: including 6 questions to be answered on a 5- point Likert scale. This construct states that people are influenced by others and enact certain behaviors as a result of their influence. In this study, subjective norms were the perception of the pregnant mothers of the opinions of important people (spouse, health center staff, midwife, physician, etc.) about the behaviors that are considered as proper newborn care.

3. Mothers' Perceived Behavioral Control: including 6 questions to be answered on a 5- point Likert scale. This construct addresses the factors which facilitate or prevent the behaviors and mothers' ability to perform the behaviors.

4. Mothers' Intention: including 3 questions to be answered on a 5- point Likert scale. Behavioral intention is the intent to enact a behavior, and when the actual behavior cannot be easily measured, behavioral intent can be used as a helpful indicator.

5- Mothers' Performance: including 6 questions to be answered on a 5- point Likert scale. In this study, proper newborn care included keeping the newborn's room temperature at the appropriate level, proper bathing, feeding the newborn with the colostrum, cleaning the umbilical cord, proper reaction to danger signs in the newborn and regular visits to health centers.

The questions have been also assessed during pregnancy based on the mothers' perceptions of whether they will enact the desired certain care behaviors if they have a baby.

To score the items in the mothers' awareness assessment on newborn care section, 1 point was given to each correct response and zero to each incorrect response. So, the points ranged from zero to 1 . The points in the constructs of the theory of planned behavior ranged from 1 to 5 .

\section{Reliabilityand Validity of Data Collection Tool}

Content validity was assessed both quantitatively and qualitatively with the help of 10 experts in the fields of health education, midwifery, pediatrics and maternal and child health. To quantitatively assess content, Content Validity Ratio (CVR) and Content Validity Index (CVI) were calculated. Obtaining CVI of at least 0.79 and CVR of at least 0.62 by referring to Lawshe's table and the number of experts in the study, the items' validity was confirmed. To determine the reliability of the questionnaire using the internal consistency, Cronbach's alpha coefficient was obtained as 0.8 for awareness, 0.75 for attitude, 0.7 for perceived behavioral control, 0.7 for behavioral intention, 0.7 for subjective norms and 0.8 for performance.

\section{Educational Intervention}


The educational intervention was designed based on the initial needs analysis of the pre-test results and was implemented in the form of 4 sessions as follows:

The first session was held for one hour focusing on enhancing the pregnant mothers' awareness of the neonatal period, newborns' needs and danger signs in newborns.

The second session was held for one hour focusing on changing the pregnant mothers' attitudes and subjective norms. According to the process recommended by Sharma et al. [20], brainstorming and group discussion techniques were used in order to modify and or change incorrect beliefs and strengthening correct ones. To enhance the mothers' belief to the importance of proper newborn care, this session covered the benefits of proper newborn care and adverse consequences of improper newborn care and its resulting economic costs. Also, in order to address subjective norms, the role of influential people, especially spouses, and their participation in performing proper newborn care was emphasized and some materials were handed to the participants in the form of educational pamphlets and booklets. In this session, role play, group discussion and critical thinking techniques were used.

The third session was held for one hour focusing on the perceived behavioral control. This session tried to make the mothers familiar with the barriers to proper care and enhancing their confidence in their ability to take care of their newborns. The educational videos were used to show the effects of behaviorfacilitating factors such as providing incentives, reducing and eliminating perceived barriers, breaking behaviors into small steps, practical demonstrations and successful experiences of mothers on perceived behavioral control.

The fourth session was held for one hour focusing on the mothers' behavioral intention and performance. The purpose of this session was making the mothers familiar with proper newborn care. Using educational videos and pictures, certain behaviors such as keeping the newborn's room temperature at the appropriate level, proper bathing, feeding the newborn with the colostrum, cleaning the umbilical cord and proper reaction to danger signs in the newborn were taught.

In order to evaluate the effectiveness of the educational intervention, the questionnaire was completed and the mother's performances were evaluated both before the intervention and one month after delivery.

\section{Data Analysis}

The data were analyzed through SPSS 20. First, descriptive statistics of mean and SD were used. Then, non-parametric Mann-Whitney and Willcoxon tests were used in cases where the data distribution was abnormal based on the Kolmogorov-Smirnov test.

\section{Ethical Considerations}

This study has been approved and financially supported by the Faculty of Health of Arak University of Medical Sciences in the form of a master's thesis in the field of Health Education and Promotion bearing 
the code No. 2957. Also, the research has been approved in the Committee of Ethics in Research of Arak University of Medical Sciences bearing the ethics code IR.ARAKMU.REC.1397.169.

\section{Results}

The average ages of the mothers in the intervention and control group were $26.4 \pm 4.76$ and $26.1 \pm 5.19$ years, respectively, which were not significantly different based on the results of the Mann-Whitney test $(p=0.310)$. Other demographic characteristics of the studied mothers are listed in Tables 1 and 2.

The results showed that before the intervention, there was no significant difference between the intervention and control groups in terms of the constructs of the theory of planned behavior. However, Mann-Whitney test showed a significant difference between the intervention and control groups in terms of constructs of the theory of planned behavior and proper newborn care behavior after the educational intervention (Table 3). Also, the performance of the intervention group regarding the proper newborn care behavior was significantly enhanced from $02.86 \pm 0.42$ before the educational intervention to $4.64 \pm 0.14$ after the intervention $(p<0.001)$.

\section{Discussion}

According to the findings of this study, the educational intervention led to a significant enhancement of mothers' performance on newborn care. This enhancement can be attributed to the educational methods, including educational videos, booklets, role plays, critical thinking, etc.

In this study, the mothers' awareness was significantly enhanced after the educational intervention. As reported by the World Health Organization, if the knowledge and awareness of parents is promoted properly, the lives of two-thirds of children dying annually because of different reasons will be saved [910]. This shows the necessity of educating mothers for and enhancing their awareness of newborn care.

However, it was found that only $37 \%$ of mothers in a study in Saudi Arabia [11], 30\% of mothers in the study of Uchenna in Nigeria[12], 58\% of mothers in the study of Sandberg in Uganda [13] and 20\% of mothers in the study of Bulto in Ethiopia [14] were aware of newborn care. Also, Tsegay reported weak awareness of $25 \%$ of midwives about newborn care [23]. All these studies emphasized on the necessity of educating mothers in this area.

It is noteworthy that the effectiveness of educational intervention in enhancing mother's awareness in the present study is consistent with the results of many other studies. The results of the study by Ghasemi et al. also reported enhanced awareness of mothers regarding the newborn care after an educational program [21]. However, the study by Salem in Saudi Arabia showed no increase in the knowledge of nurses before and six months after an educational program on neonatal growth monitoring, which is not consistent with the results of the present study. Therefore, researchers have recommended new methods of education, active participatory education and practical work, as well as supportive monitoring and evaluation [24]. 
In this study, the attitude of the mothers in the intervention group was enhanced after implementing the educational intervention. This finding is consistent with those of the studies by Mahboubi et al. on mothers' breastfeeding and Toghyani et al. on pregnancy care [26].

In the preset study, this enhancement can be the result of holding educational sessions (playing educational videos, using educational booklets with relevant pictures) about the benefits of newborn care and the adverse consequences of improper newborn care.

However, the study by Abdulkarimi et al. [27] showed thaat pregnant mothers did not have a good attitude toward taking care of their newborns due to being addicted, which is not consistent with the findings of the present study. The studies by Salem in Saudi Arabia [24], Deng in China [28] and Chia in Melbourne [29] assessed nurses' attitudes toward newborn care as low or average. The reasons can be the staff's heavy workload, insufficient education, lack of organizational support and lack of transparent protocols, especially for low birth weight babies.

Also, the study by Berhe et al. in Ethiopia evaluated mothers' attitudes toward newborn care as low in some aspects which were not compatible with their religious beliefs [30].

In another studies indicated that traditional attitudes and methods of newborn care and arbitrary use of drugs for infants are the leading causes of death and high infant mortality rate in some countries [3132].

Another finding of the present study was an increase in the subjective norm construct in the intervention group after performing the educational intervention. As most of the pregnant mothers mentioned their husbands as subjective norms, the relevant materials in this field were included in the designed educational booklets and were provided to them.

The study by Rempel in Vietnam on the role of fathers in newborn care found that greater sensitivity and interaction between father and infant could promote the emotional development of the child [33].

The study of Gu et al. on the effectiveness of TPB-based education on promoting exclusive breastfeeding in Chinese nulliparous pregnant women showed that the subjective norms of Chinese women were their husbands and mothers [22], which was consistent with the finding of the present study.

Another finding of this study was an increase in the perceived behavioral control construct in the intervention group, which is consistent with the results of some studies like Ghasemi [21] on premature newborn care. As newborn care is considered as a value among Iranian families, highlighting the value and importance of newborn care in the educational sessions could increase perceived ability of mothers and their self-confidence in this regard.

Tahir et al. also showed that one of the barriers that mothers face in early postpartum period is the low milk supply and telephone counseling for educating breastfeeding can improve breastfeeding methods [34]. 
In the study by Esan in Nigeria, $75 \%$ of mothers had perceived ability in taking care of their underweight newborns, which was due to education provided by clinical staff [35]. However, in the study by Mansourian in Iran, nurses in the neonatal intensive care units found their educational role for the parents to be poor (37\%), which was due to staff shortage, heavy workload and lack of time to educate parents [36].

In terms of behavioral intention construct, the finding of the present study showed a significant difference in the intervention group before and after the educational intervention. In order to increase behavioral intention of pregnant mothers during the educational intervention, they were informed that they could get any required information from their local health centers. Also, behavioral intention was enhanced by watching educational videos and reading the booklets. This finding was consistent with the some studies like the one by Ghaffari et al. on increasing mothers' intention for behavior of pregnant women related to exclusive breast feeding [37].

However, the results of the present study are inconsistent with those of the study by Ahmadi et al. [38], as the intention of mothers did not show any increase after breastfeeding training. It could be due to the emphasis and propaganda on the benefits of breastfeeding by the mass media and the increased initial intention of mothers before the intervention.

In their study on increasing mothers' intention to breastfeed in Spain, Bonuck et al. stated that breastfeeding counseling in two sessions before delivery and one session after delivery was effective in promoting mothers' behavioral intention in exclusive breastfeeding [39].

Promoted performance of mothers in the present study could be due to the emphasis of educational intervention sessions on learning newborn care skills by mothers participating in the intervention group. The newborn care skills emphasized in the educational intervention were cleaning the umbilical cord, bathing, proper breastfeeding, regular visits to health centers, seeing a doctor when noticing danger signs, maintaining the appropriate body temperature, etc., which all were emphasized in training sessions while providing videos and pictures.

This finding is consistent with the results of several interventional studies conducted based on TPB on various health subjects [21-22]. The results of the mentioned studies show that this theory can be effectively used to promote attitude and performance of mothers in various fields.

The positive effects of educational intervention were reported in the studies by Alam in Bangladesh on education via weekly voice messaging [17], Murthy in India on education via mHealth voice messaging service on newborn care [18], Wu in China on education using WeChat social network for improving exclusive breastfeeding [19] and de Jongh on education via SMS for improving self-efficacy skills of patients and vulnerable groups of pregnant mothers [40]. However, According to the researchers, the effectiveness of mHealth interventions need to be studied further. 
One of the limitations of the present study was collecting data though self-reporting. However, it was tried to increase the quality of the collected data by providing transparent information to mothers.

\section{Conclusion}

Considering the results of the study, the theory of planned behavior could serve as a useful model for promoting the behavior of the intervention group. Therefore, based on the obtained results, it is hoped that we can take an effective step toward the enhanced health of newborns and infants of our country by conducting more studies on this field and educating other influential individuals, especially healthcare providers and all those who have an important role in mother and child care, as the importance of the health of infants as future capitals of the country is one of the undeniable facts. Therefore, theory of planned behavior -based educational interventions are recommended to be held for better newborn care in healthcare centers and educating mothers through mass media in studies with a wider scope, longer follow-up and for other groups, including nurses, midwives and physicians.

\section{Declarations}

\section{Acknowledgment}

We would like to thank all mothers who participated in this study. This study was financially sponsored by Arak University of Medical Sciences with grant number 2957.

\section{Ethics approval and consent to participate}

All the procedures performed in the study involving human participants, were in accordance with the ethical standards. The present study was approved by the Research Council of Arak University of Medical Sciences (Grant Number:2957). Ethics committee approval code number is (IR.ARAKMU.REC. 1397. 169). Moreover informed written consent was obtained from the mothers and all the procedures performed in the study involving human participants, were in accordance with the ethical standards.

\section{Consent for publication}

Not applicable.

\section{Competing interests}

The authors have no conflict of interest to declare; the researchers have no personal or financial affiliations with the parties involved with the study.

\section{Availability of data and materials}

Upon request, we can offer onsite access to external researchers to the data analyzed at Arak University of Medical Sciences, Arak, Iran. 
Funding: The present article is taken from the Master's thesis approved by Arak University of Medical Sciences (Grant Number: 2957). The funder provided all costs of the thesis and does not have any other roles in conducting and reporting the study results.

\section{Authors' contributions}

AN, conceptualized, designed, acquisition of data; MS, conceptualized, designed, initial analysis and interpretation of data; drafted, and revised the manuscript; MKH, conceptualized, designed, initial analysis and interpretation of data; drafted, and revised the manuscript; $M Z$, conceptualized and designed the study, drafted, analyzed and interpreted the data and critically reviewed and revised the manuscript; and all authors approved the final manuscript as submitted and agreement to be accountable for all aspects of the work in ensuring that questions related to the accuracy or integrity of any part of the work are appropriately investigated and resolved.

\section{Authors and affiliation}

Azamalsadat Navabi ${ }^{1}$, Mohsen Shamsi ${ }^{2}$, Mahboobeh Khorsandi ${ }^{3}$, Maryam Zamanian ${ }^{4}$

\section{Affiliations:}

${ }^{1}$ Student Research Committee, Department of Health Education, Faculty of Health, Arak University of Medical Sciences, Arak, Iran, Email: navabi6114@gmail.com; ${ }^{2}$ Associate professor, Department of Health Education, Faculty of Health, Arak University of Medical Sciences, Arak, Iran, Email: mohsen_shamsi1360@yahoo.com dr.shamsi@arakmu.ac.ir; ${ }^{3}$ Professor, Department of Health Education, Faculty of Health, Arak University of Medical Sciences, Arak, Iran, Email: khorsandi_mahboobeh@yahoo.com and ${ }^{4}$ Assistant professor, Department of Epidemiology, Faculty of Health, Arak University of Medical Sciences, Arak, Iran, Email: maryam_zamanian23@yahoo.com.

\section{Corresponding author information:}

Address correspondence to Mohsen Shamsi, Associate professor, Department of Health Education, Faculty of Health, Arak University of Medical Sciences, Arak, Iran

E-mail: mohsen_shamsi1360@yahoo.com,dr.shamsi@arakmu.ac.ir Telefax:+98 8633686443

\section{Abbreviations}

TPB: Theory of Planned Behavior; CVR: Content Validity Ratio; CVI: Content Validity Index.

\section{References}

1-Kermani RM, Zoljalali S, Azari A, Kouhpayezadeh J. The role of training workshops of newborn cares in promotion of mothers' knowledge. Iranian Journal of Pediatrics. 2007;17(Suppl 1):41-6. 
2-Mathews T J , Driscoll Anne K. Trends in Infant Mortality in the United States, 2005-2014. NCHS Data Brief. 2017;(279):1-8. PMID: 28437240

3-Oguzhan D, Ozgur T. Does Corruption Kill? Evidence From Half a Century Infant Mortality Data. Epub 2019 May 16. PMID: $31128556 \quad$ DOI: 10.1016/j.socscimed.2019.05.017

4-Kliegman S, Geme SS. Nelson Textbook of Pediatrics, 2-Volume Set. Medicine. 2017.

5-UNICEF, WHO, World Bank, UN-DESA Population Division. Levels and trends in child mortality 2013. Maternal, newborn, child and adolescent health.(Available from:

http://www.who.int/maternal_child_adolescent/documents/levels_trends_child_mortality_2013/en/pdf). accessed Nov 2014.

6-Rafiei E, Hashemi Nazari S S, Mehrabi Y. Indirect Estimation of Infant and Child Mortality Rates in Iran: Using 2006 and 2011 Census Data. J Mazandaran Univ Med Sci. 2015; 24 (122) :32-43 URL: http://jmums.mazums.ac.ir/article-1-5232-fa.html

7-World health statistics 2014. Geneva, World Health Organization, 2014 (Available from: http://www.who.int/gho/publications/world_health_statistics/2014/en/, accessed 29 June 2014.

8-Nasution SS, Badaruddin B, Dasatjipta G, Lubis Z. Effectiveness of the Health Awareness Community Team intervention in improving the maternal and neonatal health status in Mandailing Natal (Madina) district, Sumatera Utara, Indonesia. International Journal of Medical Science and Public Health. 2015;4(6):799-804.

9-World Health Organization. Under-ive mortality.2013. Global Health Observatory (GHO). Available from: http://www.who.int/gho/child_health/mortality/mortality_under_ive_text/en. accessed Nov 2014.

10-World health statistics 2014. Geneva, World Health Organization, 2014 (Available from: http://www.who.int/gho/publications/world_health_statistics/2014/en/, accessed 29 June 2014.

11-Amani AS, Isamme A, Muhammad R, Abdullah N, Abdulrahman A, Anas K, et al.Mothers' and Caregivers' Knowledge and Experience of Neonatal Danger Signs: A Cross-Sectional Survey in Saudi Arabia. Biomed Res Int. 2019 Mar 28;2019:1750240ＰMID: 31032336 DOI: 10.1155/2019/1750240

12- Uchenna E, Ikenna KN, Chidiebere DI, Ogechukwu F, Ifeyinwa B, Ejike O. et al. Knowledge of Danger Signs in Newborns and Health Seeking Practices of Mothers and Care Givers in Enugu State, South-East Nigeria. Ital J Pediatr. 2015 Mar 21;41:18. PMID: 25888409 DOI: 10.1186/s13052-015-0127-5

13-Sandberg J, Odberg Pettersson K, Gustav A, Jerome K, Anette A. Inadequate Knowledge of Neonatal Danger Signs Among Recently Delivered Women in Southwestern Rural Uganda: A Community Survey. PLoS One. 2014 May 13;9(5):e97253. PMID: 24824364 
DOI: 10.1371/journal.pone.0097253

14-Bulto GA, Fekene DB, Moti BE, Demissie GA, Daka KB. Knowledge of neonatal danger signs, care seeking practice and associated factors among postpartum mothers at public health facilities in Ambo town, Central Ethiopia. BMC Res Notes. 2019 Aug 28;12(1):549. doi: 10.1186/s13104-019-45837.

PMID: 31462317 PMCID: PMC6714452

15-Memon J, Holakouie-Naieni K, Majdzadeh R, Yekaninejad MS, Garmaroudi G, Raza O, Nematollahi S. Knowledge, attitude, and practice among mothers about newborn care in Sindh, Pakistan. 1000- BMC Pregnancy Childbirth. 2019 Sep 6;19(1):329. doi: 10.1186/s12884-019-2479-0. PMC6729052

16-Waiswa P, Peterson S, Tomson G, Pariyo GW.Poor newborn care practices - a population based survey in eastern Uganda. BMC Pregnancy Childbirth. 2010 Feb 23;10:9. doi: 10.1186/1471-2393-10-9.

PMID:20178626

17-Alam M, Banwell C, Olsen A, Lokuge K. Patients' and Doctors' Perceptions of a Mobile Phone-Based Consultation Service for Maternal, Neonatal, and Infant Health Care in Bangladesh: A Mixed-Methods Study. JMIR Mhealth Uhealth. 2019 Apr 22;7(4):e11842. doi: 10.2196/11842. PMID:31008716

18-Murthy N, Chandrasekharan S, Prakash MP, Kaonga NN, Peter J, Ganju A, Mechael PN - The Impact of an mHealth Voice Message Service (mMitra) on Infant CareKnowledge, and Practices Among LowIncome Women in India: Findings from a Pseudo-Randomized Controlled Trial. Matern Child Health J. 2019 Dec;23(12):1658-1669. doi: 10.1007/s10995-019-02805-5. PMID:31584144

19-Wu Q, Huang Y, van Velthoven MH, Wang W, Chang S, Zhang Y. The effectiveness of using a WeChat account to improve exclusive breastfeeding in Huzhu County Qinghai Province, China: protocol for a randomized control trial. BMC Public Health. 2019 Dec 2;19(1):1603. doi: 10.1186/s12889-019-7676-2. PMCID:PMC6889429

20-Sharma M, Romas J. Theoretical foundations of health education and health promotion. Wiley Online Library; 2010.

21-Ghasemi M, Dehdari T, Mohagheghi P, Gohari MR. The effect of educational intervention based on theory of planned behavior (TPB) for improving method of care of premature infant by mother. Razi Journal of Medical Sciences. 2014;20(115):39-48.

22- Gu Y, Zhu Y, Zhang Z, Wan H. Effectiveness of a theory-based breastfeeding promotion intervention on exclusive breastfeeding in China: A randomised controlled trial. Midwifery. 2016 Nov;42:93-99. doi: 10.1016/j.midw.2016.09.010. Epub 2016 Sep 22. PMID: 27788416 
23-Tsegay Gebru T, Murugan R, Gebremariam Abrha A, Haftom Goyteom M. Knowledge and practice of immediate new-born care among midwives in central zone public health facilities, Tigray, Ethiopia: cross sectional study. BMC Res Notes. 2019 Aug 6;12(1):487. doi: 10.1186/s13104-019-4532-5. PMID: 31387618 PMCID: PMC6685261 DOI: 10.1186 / s13104-019-4532-5

24-Salem KA, Balahmar MK, Milaat W, Gabal MS. The effects of a training program on knowledge, attitude and practice of the staff of primary health care centers towards growth monitoring: an intervention study. J Egypt Public Health Assoc. 1999;74(5-6):627-49. PMID: 17219866

25- Mahboobi GF, Roozbahani N, Shamsi M. The relationship between prenatal intention to exclusive breast-feeding and mothers practice within 6 months after delivery in primipar women. DMed. 2015; 22 (6) :25-34

URL:http://daneshvarmed.shahed.ac.ir/article-1-1122-fa.html

26- Toughyani R, Ramezani M A, Izadi M, shahidi S, aghdak P, Motie Z et al . The Effect of Prenatal Care Group Education on Pregnant Mothers' Knowledge, Attitude and Practice. Iranian Journal of Medical Education. 2008; 7 (2) :317-324

URL: http://ijme.mui.ac.ir/article-1-717-fa.html

27- Abdol karimi M. prophecy selecttion kind of Behavior and prenatal care on Addicted pregnant woman giving birth based on theory of planned behavior, Journal of Hamedan University of Medical Sciences. 2015; 3(2): 14-22.

28-Deng Q, Zhang Y, Li Q, Wang H, Xu X. Factors that have an impact on knowledge, attitude and practice related to kangaroo care: National survey study among neonatal nurses. J Clin Nurs. 2018 Nov;27(21-22):4100-4111. doi: 10.1111/jocn.14556. Epub 2018 Jul 23. PMID: 29893432

29-Chia P, Sellick K, Gan S. The attitudes and practices of neonatal nurses in the use of kangaroo care. Aust J Adv Nurs. 2006 Jun-Aug;23(4):20-7.PMID: 16800216

30-Berhe M, Medhaniye AA, Kahsay G, Birhane E, Abay M. Essential neonatal care utilization and associated factors among mothers in public health facilities of Aksum Town, North Ethiopia, 2016. PLoS One. 2017 Apr 19;12(4):e0175902. doi: 10.1371/journal.pone.0175902. eCollection 2017. PMID: 28423043 PMCID: PMC5397028

31-Syed U, Khadka N, Khan A, Wall S. Care-seeking Practices in South Asia: Using Formative Research to Design Program Interventions to Save Newborn Lives. J Perinatol. 2008 ;28 Suppl 2:S9-13.

PMID: $19057572 \quad$ DOI: 10.1038/jp.2008.165

32-Bogale D, Markos D. Knowledge of Obstetric Danger Signs Among Child Bearing Age Women in Goba District, Ethiopia: A Cross-Sectional Study. BMC Pregnancy Childbirth. 2015 :29;15:77. 
33-Rempel LA, Rempel JK, Moore KC. Relationships between types of father breastfeeding support and breastfeeding outcomes. Maternal \& child nutrition. 2017; 13(3): 20.

34- Tahir NM, Al-Sadat N. Does telephone lactation counseling improve breastfeeding practices? A randomised controlled trial. Int J Nurs Stud. 2013 Jan;50(1):16-25. doi: 10.1016/j.ijnurstu.2012.09.006. Epub 2012 Oct $17 . \quad$ PMID:23084438

35-Esan O, Fatusi A, Ojo T. The knowledge versus self-rated confidence of facility birth attendants with respect to maternal and newborn health skills: the experience of Nigerian primary healthcare facilities. Malawi Med J. 2019 Sep;31(3):212-220. doi: 10.4314/mmj.v31i3.8. PMID: 31839891 PMCID: PMC6895387 DOI: 10.4314 / mmj.v31i3.8

36-Mansourian M, Ziapour A, Kazemian M, Damanabad ZH, Rastegarimehr B, Mirzaei A, et al. Assessment of educational performance of nurses in neonatal intensive care unit from parents' perspective. J Educ Health Promot. 2020 Jan 30;9:8. doi: 10.4103/jehp.jehp_371_19. eCollection 2020. PMID: 32154303 PMCID: PMC7032028

37-Ghaffari M, Rakhshanderou S, Harooni J, Mehrabi Y, Ebrahimi A. Prenatal Interventional Program About Mothers' Behavior Related to Exclusive Breast Feeding: Findings of Planned Behavior TheoryBased Research. J Lifestyle Med. . 2019 Jul;9(2):143-149. PMID: 31828034

DOI: 10.15280/jlm.2019.9.2.143

38- Ahmadi M, Moeini B, Nasiri M. Impact of Educational Program Based on the Theory of Planned Behavior on Primiparous Pregnant Women's Knowledge and Behaviors Regarding Breast Feeding. hc journal. 2014;16(1):19-31.

39-Bonuck KA, Trombley M, Freeman K, McKee D. Randomized, controlled trial of a prenatal and postnatal lactation consultant intervention on duration and intensity of breastfeeding up to 12 months. Pediatrics. 2005 Dec;116(6):1413-26.

40- de Jongh T, Gurol-Urganci I, Vodopivec-Jamsek V, Car J, Atun R. Mobile phone messaging for facilitating self-management of long-term illnesses. Cochrane Database Syst Rev. 2012 Dec 12;12:CD007459. doi: 10.1002/14651858.CD007459.pub2. PMID: 23235644

\section{Tables}

Table 1. Comparison of the intervention and control groups, concerning the quantitative demographic variables 


\begin{tabular}{lccccl}
\hline \multicolumn{1}{c}{ Group } & \multicolumn{2}{c}{ Intervention } & \multicolumn{2}{c}{ Control } & P-Value* \\
Variable & Mean & SD & Mean & SD & -Valu \\
Age mothers (years) & 26.4 & 4.76 & 26.1 & 5.19 & 0.310 \\
Age marriage mothers (years) & 22.42 & 2.13 & 22.14 & 2.31 & 0.755 \\
Age of pregnancy & 28.22 & 3.33 & 27.5 & 2.91 & 0.389 \\
BMI (Weight $(\mathrm{kg}) /$ height $\left.\left(\mathrm{m}^{2}\right)\right)$ & 26.60 & 3.9 & 26.99 & 4.12 & 0.34 \\
\hline
\end{tabular}

*Mann-Whitney Test

Table 2. Comparison of the intervention and control groups, concerning the qualitative demographic variables

\begin{tabular}{|c|c|c|c|c|c|c|}
\hline \multicolumn{2}{|c|}{ Group } & \multicolumn{2}{|c|}{ Intervention } & \multicolumn{2}{|c|}{ Control } & \multirow[b]{2}{*}{$\begin{array}{l}\text { P- } \\
\text { Value* }\end{array}$} \\
\hline Variable & & $\begin{array}{l}\text { Frequency } \\
(\mathrm{N})\end{array}$ & $\begin{array}{l}\text { Percent } \\
(\%)\end{array}$ & $\begin{array}{l}\text { Frequency } \\
(\mathrm{N})\end{array}$ & $\begin{array}{l}\text { Percent } \\
(\%)\end{array}$ & \\
\hline \multirow{2}{*}{ Mother job } & Housewife & 45 & 90 & 44 & 88 & 0.62 \\
\hline & Employee & 5 & 10 & 6 & 12 & \\
\hline \multirow[t]{3}{*}{ Husband's job } & Employee & 14 & 28 & 8 & 16 & 0.174 \\
\hline & $\begin{array}{l}\text { Manual } \\
\text { worker }\end{array}$ & 10 & 20 & 7 & 14 & \\
\hline & Unemployed & 26 & 52 & 35 & 70 & \\
\hline \multirow{3}{*}{$\begin{array}{l}\text { Level of Educational } \\
\text { mother }\end{array}$} & Elementary & 1 & 2 & 2 & 4 & 0.75 \\
\hline & Diploma & 8 & 16 & 10 & 20 & \\
\hline & University & 41 & 82 & 38 & 76 & \\
\hline \multirow{3}{*}{ Husband's } & Elementary & 12 & 24 & 14 & 28 & 0.824 \\
\hline & Diploma & 24 & 48 & 21 & 42 & \\
\hline & University & 14 & 28 & 15 & 30 & \\
\hline \multirow[t]{2}{*}{ Residential status } & Personal & 21 & 42 & 20 & \multirow{2}{*}{\multicolumn{2}{|c|}{$\begin{array}{l}400.599 \\
60\end{array}$}} \\
\hline & Rental & 29 & 58 & 30 & & \\
\hline
\end{tabular}

* Chi-square

Table 3. Comparison of the intervention and control groups, concerning the TPB, before and after the intervention 


\begin{tabular}{|c|c|c|c|c|c|c|}
\hline \multirow[b]{2}{*}{ Variable } & \multirow[t]{2}{*}{ Group } & \multicolumn{2}{|c|}{ Intervention } & \multicolumn{2}{|c|}{ Control } & \multirow[b]{2}{*}{ P-value ${ }^{a}$} \\
\hline & & Mean & SD & Mean & SD & \\
\hline \multirow[t]{3}{*}{ Knowledge } & Before & 0.61 & 0.25 & 0.55 & 0.210 & 0.230 \\
\hline & After & 0.825 & 0.324 & 0.745 & 0.144 & 0.001 \\
\hline & P-value ${ }^{b}$ & 0. & 01 & 0.772 & & \\
\hline \multirow[t]{3}{*}{ Attitude } & Before & 3.08 & 0.37 & 3.28 & 0.33 & 0.466 \\
\hline & After & 4 & 0.01 & 3.51 & .42 & 0.001 \\
\hline & P-value ${ }^{b}$ & 0.001 & & 0 . & 45 & \\
\hline \multirow[t]{3}{*}{ Subjective norm } & Before & 2.50 & 0.311 & 2.56 & 0.268 & 0.413 \\
\hline & After & 3.70 & 0.296 & 2.43 & 0.235 & 0.001 \\
\hline & P-value ${ }^{b}$ & 0.001 & & & .167 & \\
\hline \multirow[t]{3}{*}{ Perceived behavior control } & Before & 3.65 & 0.425 & 3.92 & 0.267 & 0.064 \\
\hline & After & 4.34 & 0.367 & 3.99 & 0.315 & 0.001 \\
\hline & P-value ${ }^{b}$ & 0.001 & & 0.279 & & \\
\hline \multirow[t]{3}{*}{ Intention behavior } & Before & 3.33 & 0.301 & 3.44 & 0.061 & 0.432 \\
\hline & P-value ${ }^{b}$ & 4.54 & 0.219 & 4.02 & 0.272 & 0.001 \\
\hline & After & 0.001 & & & 67 & \\
\hline \multirow[t]{3}{*}{ Performance } & Before & 2.86 & 0.42 & 2.45 & 0.259 & 0.135 \\
\hline & After & 4.64 & 0.14 & 3.32 & 0.555 & 0.001 \\
\hline & $\mathrm{P}$-value ${ }^{\mathrm{b}}$ & \multicolumn{2}{|c|}{0.001} & \multicolumn{2}{|c|}{0.167} & \\
\hline
\end{tabular}

a Mann-Whitney Test

b Willcoxon

Figures 


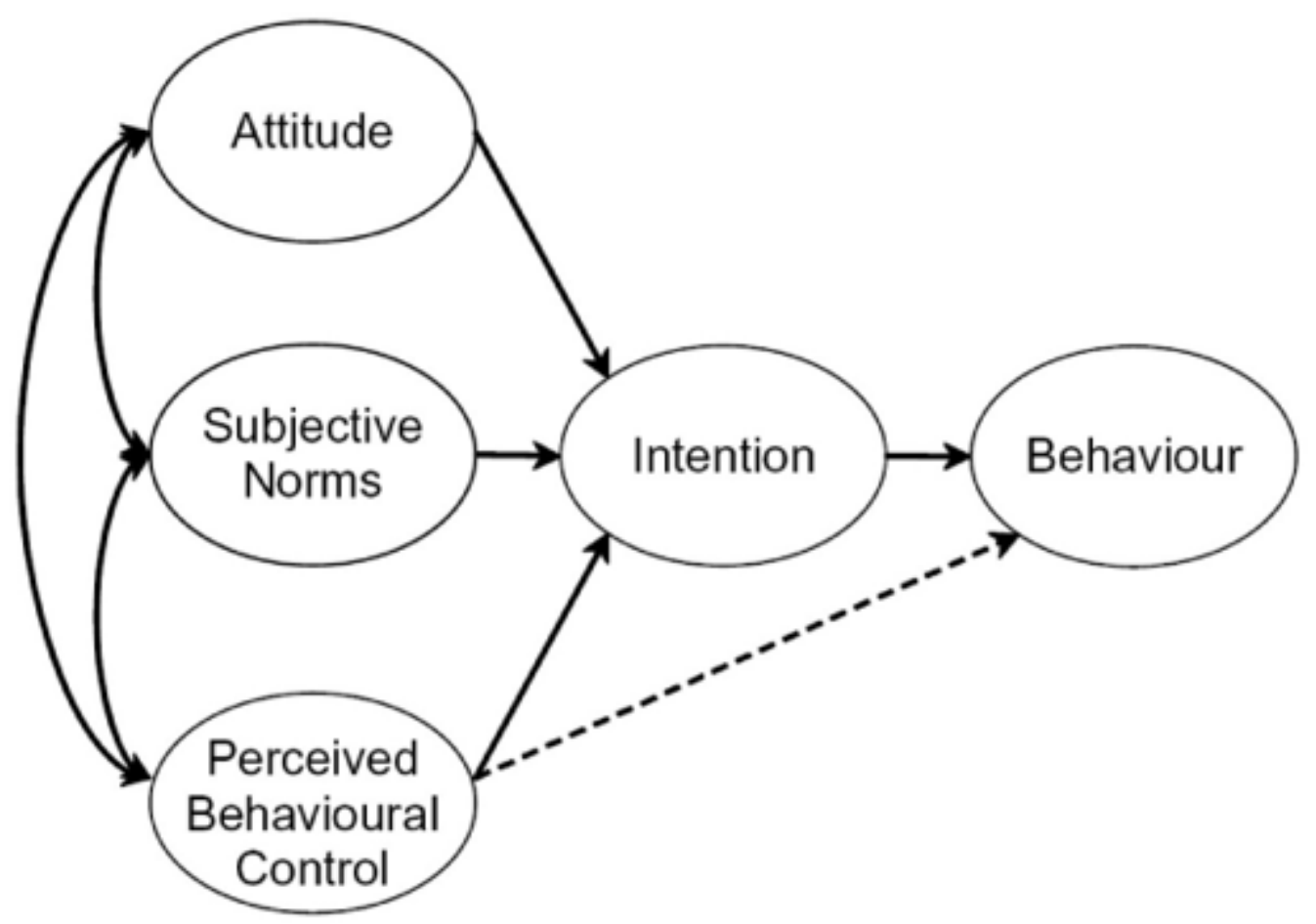

Figure 1

Theory of planed behavior (TPB) In this model, by developing attitude and subjective norms to neonatal care, along with training on the perceived behavior control as incentives for mothers and increasing their self-efficacy, intention and behavior neonatal care will be improved in these mothers.

\section{Supplementary Files}

This is a list of supplementary files associated with this preprint. Click to download.

- formula.docx 